\title{
Is presumed consent the answer to organ shortages?
}

Veronica English deputy head of medical ethics, British Medical Association, London WC1H 9JP venglish@bma.org.uk

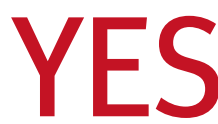
In the UK in the year to 31 March 2007, 440 people died waiting for a donated organ (UK Transplant, personal communication). At the same time bodies were buried or cremated intact-it seems likely that this was not because those people objected to donating their organs but simply because they never got around to making their wishes known. Surveys show that $90 \%$ of the UK population support organ donation, ${ }^{1}$ yet our current law assumes, when people die, that they are in the minority who do not wish to donate. By changing the default position to presumed consent-assuming people want to donate unless there is evidence to the contrary-we can help save and transform more lives while respecting the wishes of those who want to donate and protecting the rights of those who do not.

Although $90 \%$ of the population support donation, only $23 \%$ have registered their wish to donate, ${ }^{2}$ and so the decision falls to the family when they have just been told that their relative has died or is dying. Not surprisingly, when they do not know their relative's wishes a large number (40\%) opt for the default position, which is not to donate. ${ }^{3}$ Despite major efforts to improve transplantation rates over the past decadethrough publicity and education, simplifying the registration process, and changes in legislationthe gap between the number of organs available and the number

\section{The organs would not be used if it would cause severe distress to the relatives}

sections of the public are informed and can register an objection easily.

With the new system in place, when a person is identified as a potential donor doctors must check the opt-out register. If the person has not opted out, the relatives are informed and, as an added safeguard, are asked if they are aware if the person has any unregistered objection. If the answer is no, the relatives are informed of the intention to proceed with donation. However, the organs would not be used if it would cause severe distress to the relatives. In this way, relatives are still involved but the approach is easier for all concerned.

Of course, the key question is does it work? It is notoriously difficult to prove a causal relation between particular determinants and donation rates and to extrapolate from the experiences of one country to another. Nevertheless, careful analyses seem to indicate that presumed consent improves donation rates. Analysis of 28 countries found that those countries that consistently implemented a policy of presumed consent had higher donation rates than those that did not. ${ }^{6}$ Abadie and Gay did a detailed regression analysis comparing 22 countries over 10 years taking account of determinants that might affect donation rates: gross domestic product per capita, health expenditure, religious beliefs, legislative system, and number of deaths from traffic crashes and cerebrovascular diseases. ${ }^{7}$ They concluded that "When other determinants of donation rates are accounted for, presumed consent countries have roughly $25-30 \%$ higher donation rates than informed consent countries." One explanation of people needing a transplant shows no sign of narrowing and the waiting list for organs stands at an all time high. ${ }^{4}$

\section{How would presumed consent work?}

Presumed consent is often portrayed in its extreme form where, if an individual has not opted out, the organs will automatically be available for donation. However, the system proposed for the UK would continue to involve the family. ${ }^{5}$ Before a change to presumed consent there would be extensive publicity advising people how to opt out. Mechanisms must be in place to ensure all is that, even if the family has the final say, countries with presumed consent legislation have fewer refusals.

Spain has the highest recorded donor rate in the world, at 35.1 donors per million population (compared with 12.8 in the UK). ${ }^{8}$ So what can we learn from there? Spain has a presumed consent system (although in practice relatives are consulted) and has invested heavily in transplantation ${ }^{9}$ : over a decade the number of transplant coordinator teams increased from 25 to $139 .{ }^{10}$ This combination of a system of presumed consent, which portrays a positive attitude towards donation, major financial investment, and good organisation, seems to be the way forward.

\section{Public attitudes}

Any such change must have public and professional support. This seems to be increasing in the UK, ${ }^{11}$ although we have yet to see the sustained education and debate that is required. It is not acceptable for the government to continue arguing that there is a lack of support for presumed consent without any serious attempt to test this assertion.

We all have the same aim: to improve donation rates. Current efforts to achieve this should be supported, but how long should we continue to doggedly pursue the same strategy that has failed, so dramatically, to improve donation rates over the past decade? We cannot afford to wait another five years before beginning to consider alternatives because the longer we procrastinate the more lives are lost unnecessarily. Now is the time for a public debate about presumed consent so we are ready to implement it when, as seems likely, we are having the same debate in five years' time.

A move to presumed consent is the way forward. It would be

- Good for those who support donation-because they have to make no effort to ensure their wishes are followed

- Good for those who oppose donationbecause their wishes will be formally recorded and must be followed

- Good for familiesbecause they are relieved of the burden of decision making when they have just been told their relative has died or is dying

- Good for those who need a transplantbecause with more organs available more lives can be saved.

Competing interests: None declared. References are in the full version on bmj.com 


\section{The supply of donor organs cannot keep up with demand. Veronica English argues that assuming people want to donate unless there is contrary evidence will increase availability, but Linda Wright believes the problem is more complex}

Linda Wright bioethicist, University Health Network and Joint Centre for Bioethics, University of Toronto, Toronto General Hospital, Toronto ON, Canada M5G 2N2 Linda.wright@uhn.on.ca

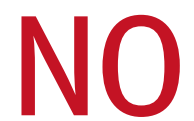

Presumed consent will not answer the organ shortage. It has not eliminated waiting lists despite evidence that it increased organ donation in some countries. ${ }^{1}$ Systems of opting out do not ensure higher rates of donation than opting-in systems. ${ }^{2}$ Strategies to encourage people to donate and public education seem to help and are independent of whether people have to opt in or out. The shortage of organs has multiple causes; no single strategy is likely to solve it.

\section{Controversy over presumed consent}

Presumed consent refers to laws that permit the procurement of organs without explicit permission. ${ }^{3}$ The term is used widely in discussion of systems of opting in or opting out of organ donation. The US Institute of Medicine is concerned that the introduction of presumed consent without the appropriate public support could reduce donation rates in countries where autonomy is highly prized, such as North America. ${ }^{4}$ People may be more likely to

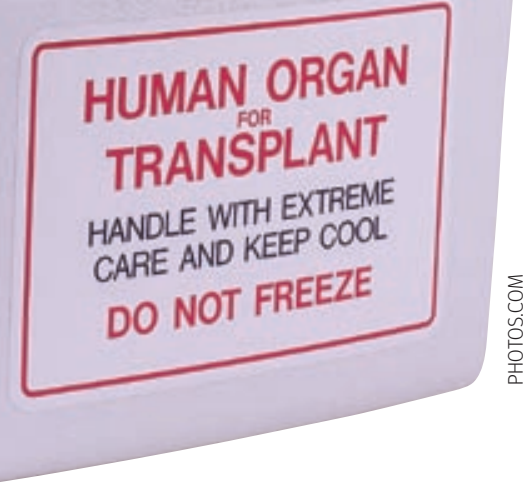

donate when they feel they retain control of that decision rather than the law dictating that donation should take place. Brazil had to withdraw its system of presumed consent because it aggravated mistrust in the healthcare system. ${ }^{4}$

\section{Influences on donation rates}

The effect of presumed consent is hard to evaluate as it is implemented in different ways in different contexts, with different results. More organs may be available for transplantation because of the number of intensive care beds, transplant surgeons, coordinators, and specialised units or because of

More people might
donate if they were
offered financial
incentives

\section{Strategies to encourage donation}

Currently organ donation is conceptualised as an altruistic act, and legislation exists in most countries to outlaw any material benefit for donation. However, more people might donate if they were offered financial incentives. Another possible incentive would be to give increased priority for a donor organ to people who have recorded their willingness to donate. ${ }^{12}$ Tactics to identify those who want to donate and encouraging them to inform their families about their wishes would inform the procurement system about a donor's wishes and facilitate decision making on organ donation. which organs are needed and the predominant cause of deaths. ${ }^{5}$ The rate of donation in France in 2005 was 22.2 donors per million population while in Spain it was 35.1 per million. ${ }^{6}$ Both countries operate presumed consent and routinely ask families for their consent to donation, yet their organ donation rates vary greatly. In Austria, where such permission is not routinely sought, the rate of donation was 24.8 in 2005 . $^{6}$

Spain expands its donor pool by using declarations of death based on not only neurological but also cardiocirculatory criteria-that is, declaring death when the cardiorespiratory system is believed to have stopped functioning. This system has been credited with increasing donation rates in some parts of the US, which has an opting-in system. ${ }^{78}$ Singapore's law on presumed consent makes exemptions for Muslims on religious grounds. ${ }^{9}$ The need for public acceptance of organ donation means that a strategy may work in one society, but not another.

Other factors that might explain Spain's enviable rates of organ donation include an environment that treats organ donation as a priority. Transplantation has a strong support system, a dedicated budget, and accountability for performance. ${ }^{10}$ Staff are trained how to approach grieving families about organ donation. Donation will not increase without the necessary equipment, trained staff, and intensive care beds to enable a potential donor to donate viable organs. These institutional factors contribute to the donation rate and seem to account for some of the variation in rates of organ availability. ${ }^{11}$
Donor cards would surely help families decide whether to donate a relative's organs. ${ }^{13}$

We must not forget that many countries today are multicultural societies, where diverse groups view organ donation differently. Trust in the healthcare system is not universal. Presumed consent could alienate even further those groups that lack this trust, and feed negative attitudes towards organ donation. Engagement of the leaders of communities and attention to religious and cultural beliefs and practices around organ donation may help the public to build the necessary trust to favour organ donation.

\section{Meeting demand}

Given the challenge of comparing behaviours in societies with different belief systems and laws, it is imperative that we increase our knowledge of the variables influencing donation rates. Organ donation has increased in Spain, where presumed consent and additional strategies are used. Are some of these variables more effective than others? Are any or all of them adaptable and acceptable to other countries?

Finally, meeting the demand for organs may require not only increasing organ supply but also optimising prevention of disease and selection of recipients. Given the multifactorial nature of the problem, presumed consent alone will not solve the organ shortage.

Competing interests: None declared.

References are in the full version on bmj.com

WHERE DO YOU STAND ON THE ISSUE? Vote now on bmj.com 